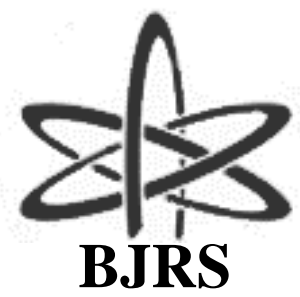

\author{
BRAZILIAN JOURNAL \\ $\mathrm{OF}$ \\ RADIATION SCIENCES \\ 09-02 (221) 01-16
}

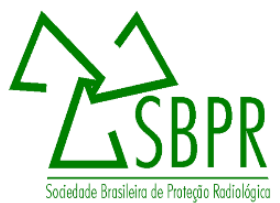

\title{
Study of new routes for purification of fission ${ }^{99} \mathrm{Mo}$
}

\author{
Damasceno, M. O., Marques, F. A. da S., Dias, R. R., Santos, \\ J. L., Forbicini, C. A. L. G. O. \\ Instituto de Pesquisas Energéticas e Nucleares (IPEN / CNEN - SP) \\ Chemistry and Environmental Centre \\ Av. Professor Lineu Prestes 2242, 05508-000, Sao Paulo, SP, Brazil \\ molidam@ipen.br
}

\begin{abstract}
${ }^{99 \mathrm{~m}} \mathrm{Tc}$ is the most used medical radioisotope in the world, especially for diagnosis procedures. It is originated in the radioactive decay of ${ }^{99} \mathrm{Mo}$, which in turn is one of the fission products of the uranium irradiation that occurs in nuclear reactors. The chemical processing of ${ }^{99} \mathrm{Mo}$ might be lined up in several steps according to the characteristics of the targets or the local requirements in order to separate it from other fission products. In this work, two routes of ${ }^{99}$ Mo purification, MR1 and MR2, were purposed as an alternative method to be set up in the Brazilian Multipurpose Reactor project. The MR1 route consisted by three consecutives chromatographic columns packed with strong anionic resin, Chelating resin, and aluminum oxide, respectively. The MR2 route was arranged in two chromatographic columns and a sublimation oven. The final yield for the MR1 was $84.4 \%$ and the overall time process was about 7 hours, performing the highest final ${ }^{99}$ Mo recovery efficiency, high decontamination degree and a shorter process time compared to the MR2.
\end{abstract}

Keywords: ${ }^{99}$ Mo fission, ${ }^{99}$ Mo purification, ${ }^{99}$ Mo sublimation. 


\section{INTRODUCTION}

Nowadays, ${ }^{99 \mathrm{~m}} \mathrm{Tc}$ is the main radioisotope used in nuclear medicine worldwide due to its pure gamma decay of low energy (140 keV) and short half-life (6.02 hours). It is commonly combined to other molecules known as markers, which in turn have an affinity for some specific organ or tissue [1,2]. In the world, more than 22 million medical procedures are performed annually for diagnostic imaging tests applying ${ }^{99 \mathrm{~m}} \mathrm{Tc}[3]$.

${ }^{99 \mathrm{~m}} \mathrm{Tc}$ can be provided for medical centers throughout the country using ${ }^{99} \mathrm{Mo} /{ }^{99 \mathrm{~m}} \mathrm{Tc}$ generators Therefore, ${ }^{99} \mathrm{Mo}$ plays an important role as a precursor for the global supply of ${ }^{99 \mathrm{~m}} \mathrm{Tc}$. The production of fission ${ }^{99} \mathrm{Mo}$ initiates with the irradiation of ${ }^{235} \mathrm{U}$ targets ( $\mathrm{UAl} \times \mathrm{x} / \mathrm{Al}$ ) into a nuclear reactor, followed by a chemical processing for purification, where the ${ }^{99} \mathrm{Mo}$ is separated from the other undesirable radionuclides that are produced in the fission process as well. Then, the bulk ${ }^{99} \mathrm{Mo}$ is divided and shipped to generators manufacturing units $[4,5]$.

After the Mo shortages in 2008-2009, when some producing reactors were disabled, several countries were led to planning new strategies for ${ }^{99}$ Mo production. Particularly in Brazil, it was created the BMR project (Brazilian Multipurpose Reactor) as an action to meet the local demand for fission radioisotopes. The BMR project presumes the construction of a nuclear reactor, chemical processing facilities, and research laboratories [6,7].

The radiochemical purification is a relevant step on the ${ }^{99}$ Mo production process due to the complexity of the separation of ${ }^{99} \mathrm{Mo}$ from the other fission radionuclides generated in the uranium decay, and the purification method depends on the production process adopted in the nuclear plant.

There are many processes for ${ }^{99}$ Mo production currently in use worldwide, and some of them are derived from the well-known KSA process (Karlsruhe-Sameh Aluminide) [8]. This process was developed initially in Germany and applied on an industrial scale in the Netherlands in 1996, where it became a reliable, safe, and high efficient industrial-scale process ran by the Mallinckrodt Company at Petten (Netherland). Later, it was adopted by other countries such as Argentina and South Africa [9-12]. 
The ROMOL-99 (Rossendorf Molybdenum-99) also is a high efficient German process that was implemented in Pinstech (Pakistan). It also can be implemented on a smaller scale of production and presents an interesting sublimation step at the end of the purification process [13].

According to KSA and ROMOL-99 methodology, the uranium target is dissolved in a strong alkaline media, resulting in a solution containing ${ }^{99} \mathrm{Mo}$ and other radionuclides as contaminants. This solution is treated by packed-columns chromatography and sublimation (ROMOL-99) to achieve the required radiochemical purity.

In this work, two routes (MR1 and MR2) of ${ }^{99}$ Mo purification were studied in order to contribute to setup of the production process on BMR project facilities. These routes were based on two established processes, KSA and ROMOL-99. A flow chart of the reference processes routes and the studied is shown in Fig. 1.

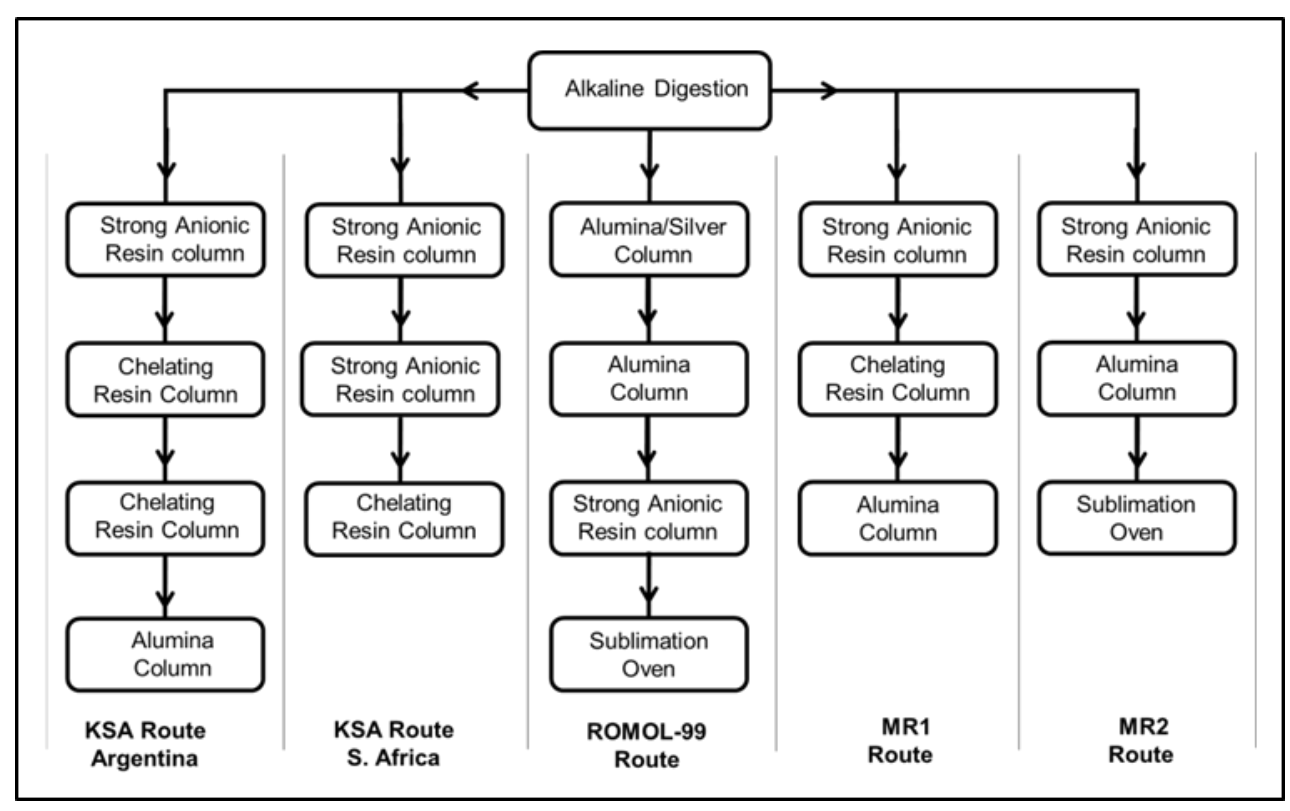

Figure 1: Some routes of ${ }^{99}$ Mo purification and their main steps.

\section{MATERIALS AND METHODS}

The MR routes were composed mainly of chromatographic columns as in the reference processes. In MR $1{ }^{99}$ Mo purification was arranged in three followed chromatographic columns. The 
first column was packed with strong anionic resin Dowex $1 \mathrm{x} 8$, the second one with chelating resin Chelex-100, and lastly, a column with alumina an inorganic ion-exchanger. In MR2 also was performed in three steps, where the first and second ones were carried out by chromatography using a Dowex 1x8 and alumina columns, respectively, and the third step was a sublimation process. Both routes' steps are shown in Figure 1.

The routes were tested using loading solutions previously prepared, which were added various elements and radionuclides in order to simulate yielded a sample produced by an alkaline dissolution process of uranium targets. The solutions contained $\mathrm{NaOH} 1 \mathrm{~mol} \cdot \mathrm{L}^{-1}$; $\mathrm{Al} 25 \mathrm{~g} \cdot \mathrm{L}^{-1}$; Mo $5 \mathrm{mg} \cdot \mathrm{L}^{-1}$; I $1 \mathrm{mg} \cdot \mathrm{L}^{-1}$; Ru $5 \mathrm{mg} \cdot \mathrm{L}^{-1}$; Te $2 \mathrm{mg} \cdot \mathrm{L}^{-1}$ and $\mathrm{Zr} 7 \mathrm{mg} \cdot \mathrm{L}^{-1}$, besides a countless mass of ${ }^{99} \mathrm{Mo}$, ${ }^{131} \mathrm{I},{ }^{103} \mathrm{Ru},{ }^{121} \mathrm{Te}$, and ${ }^{95} \mathrm{Zr}$. The tests were carried out using $1.5 \mathrm{~L}$ of loading solution, in duplicate.

The used material for experimental arrangement included hoses, valves, and peristaltic pumps to control the volume and flow directions of the radioactive solutions, considering the scale of the purification process.

\subsection{MR1 route}

For the first step of the MR1 route were used glass column $13 \times 2.5 \mathrm{~cm}$ packed with $35 \mathrm{~g}$ of Dowex 1x8 anionic resin with no pre-conditioning procedure. Firstly, the column was percolated with $1.5 \mathrm{~L}$ of the loading solution at a flow rate of $40 \mathrm{~mL} \cdot \mathrm{min}^{-1}$. After that, the packed-bed was washed twice: first, with $500 \mathrm{~mL}$ of $1 \mathrm{~mol} \cdot \mathrm{L}^{-1} \mathrm{NaOH}$ at $20 \mathrm{~mL} \cdot \mathrm{min}^{-1}$, and then, with $500 \mathrm{ml}$ of distilled water at $20 \mathrm{~mL} \cdot \mathrm{min}^{-1}$. Finally, the ${ }^{99} \mathrm{Mo}$ was collected by elution with $1.0 \mathrm{~mol} \cdot \mathrm{L}^{-1} \mathrm{Na}_{2} \mathrm{SO}_{4}$ at $3 \mathrm{~mL} \cdot \mathrm{min}^{-1}$.

The ${ }^{99}$ Mo solution $(210 \mathrm{~mL})$ eluted from the Dowex $1 \times 8$ column was added to a complexing solution containing $140 \mathrm{~mL}$ of $6 \mathrm{~mol} \cdot \mathrm{L}^{-1} \mathrm{H}_{2} \mathrm{SO}_{4}, 18 \mathrm{~mL}$ of $6 \mathrm{~mol} \cdot \mathrm{L}^{-1} \mathrm{NH}_{4} \mathrm{SCN}, 14 \mathrm{~mL}$ of 0.5 $\mathrm{mol} \cdot \mathrm{L}^{-1} \mathrm{KI}$ and $35 \mathrm{~mL}$ of $0.8 \mathrm{~mol} \cdot \mathrm{L}^{-1} \mathrm{Na}_{2} \mathrm{SO}_{3}$. The solution was reserved for 15 minutes for the formation of the $\left[\mathrm{Mo}(\mathrm{SCN})_{6}\right]^{-}$complex, before the elution through the Chelex column.

After that, the solution was percolated at a flow rate of $5 \mathrm{~mL} \cdot \mathrm{min}^{-1}$ in the glass column $(10 \mathrm{x} 1$ $\mathrm{cm}$ ) filled with $7 \mathrm{~g}$ of resin Chelex previously conditioned with $50 \mathrm{~mL}$ of complexing solution. The bed was washed with $50 \mathrm{~mL}$ of complexing solution and the ${ }^{99} \mathrm{Mo}$ was eluted with $1 \mathrm{~mol} \cdot \mathrm{L}^{-1} \mathrm{NaOH}$ at a flow rate of $1 \mathrm{~mL} \cdot \mathrm{min}^{-1}$. 
In the third step, it was used a glass column $(10 \times 1 \mathrm{~cm})$ filled with $10 \mathrm{~g}$ of acid alumina, with no pre-conditioning treatment. The eluted solution from the Chelex column was acidified adding $1 \mathrm{~mol} \cdot \mathrm{L}^{-1} \mathrm{HNO}_{3}$ until completing the volume of $80 \mathrm{~mL}$, approximately. This solution was percolated through the alumina bed at $3 \mathrm{~mL} \cdot \mathrm{min}^{-1}$ flow rate After that the column was washed with $50 \mathrm{~mL}$ of distilled water, and then with $50 \mathrm{~mL}$ of $0.01 \mathrm{~mol} \cdot \mathrm{L}^{-1} \mathrm{NaOH}$. The elution was done with 1 $\mathrm{mol} \cdot \mathrm{L}^{-1} \mathrm{NaOH}$ solution at $1 \mathrm{~mL} \cdot \mathrm{min}^{-1}$ flow rate.

\subsection{MR2 route}

The MR2 route also used ion-exchange chromatography, but a thermal separation by sublimation was included. The purification was started using a chromatographic column packed with Dowex 1x8 resin, and a second column filled with the alumina was adopted in the followed step.

Both columns (with Dowex and alumina, respectively) were carried out based on the same method described previously for the MR1 route, however, instead of $1.0 \mathrm{~mol} \cdot \mathrm{L}^{-1} \mathrm{NaOH}$ as the eluting solution, it was used $1.0 \mathrm{~mol} \cdot \mathrm{L}^{-1} \mathrm{KHCO}_{3}$ in the first column (Dowex) and $0.1 \mathrm{~mol} \cdot \mathrm{L}^{-1}$ $\mathrm{NH}_{4} \mathrm{OH}$ in the second one (alumina).

Before the sublimation step, the sample was pre-treated by evaporation. The eluted solution from chromatographic steps was heated at $80^{\circ} \mathrm{C}$ in a heating plate, for removing of excessed water and reducing of volume until about $5 \mathrm{~mL}$. Then, this volume was transferred to a small platinum crucible, and heated until dryness.

After cooling, the crucible containing ${ }^{99}$ Mo solid residue was placed inside a quartz tube, which was accommodated in a horizontal tubular oven under a controlled temperature. The sample was heated to sublimation temperature at a heating rate of $15^{\circ} \mathrm{C} \cdot \mathrm{min}^{-1}$, an isotherm of 10 minutes at 850 ${ }^{\circ} \mathrm{C}$, and an airflow rate of $5 \mathrm{~L} \cdot \mathrm{h}^{-1}$ inside the tube.

At the end of sublimation, the molybdenum oxide remained impregnated in the inner surface of the tube. It was carefully recovered by washing the tube with $10 \mathrm{~mL}$ of $1 \mathrm{~mol} \cdot \mathrm{L}^{-1} \mathrm{NaOH}$, using a washing apparatus designed on Instituto de Pesquisas Energéticas e Nucleares (IPEN) for this purpose. A schematic figure of washing tubes is shown in Fig. 2. 


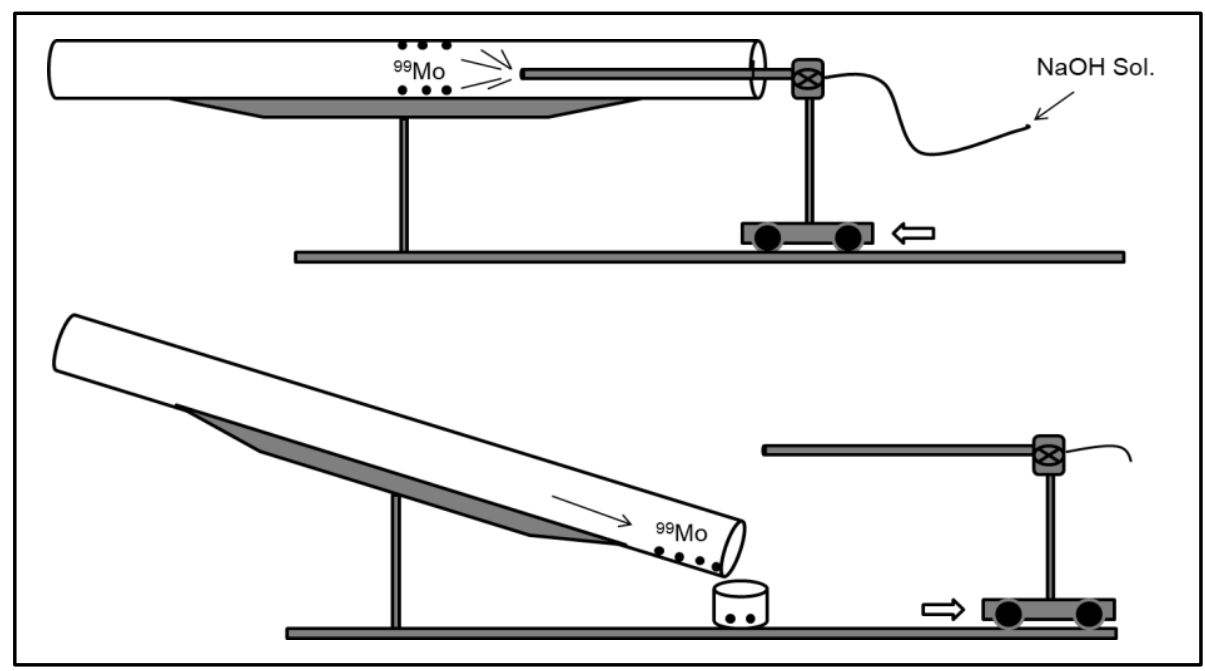

Figure 2: Tube washing scheme for sublimated ${ }^{99}$ Mo recovery.

\subsection{Measures of radioactive activities}

All experiments were carried out in duplicate at $25^{\circ} \mathrm{C}$ and $10 \mathrm{~mL}$ of solutions (from loading, eluting, and washing) were collected at the end of each step for the measure of activities and step efficiency calculations.

The measurements of the radioactive activities of the samples studied were performed using a gamma spectrometer with coaxial hyperpure Germanium detector (HPGe) model GX 1518, coupled to a Canberra Inc. multi-channel acquisition system.

The main emission peaks of the radioisotopes involved in the purification route tests were selected for the measures: ${ }^{99} \mathrm{Mo}(739 \mathrm{keV}),{ }^{131} \mathrm{I}(636 \mathrm{KeV}),{ }^{103} \mathrm{Ru}(497 \mathrm{keV}),{ }^{121} \mathrm{Te}(573 \mathrm{keV})$, and ${ }^{95} \mathrm{Zr}(756 \mathrm{keV})$. The yield rates of the experiments were calculated by equation 1 :

$$
R=\left(\frac{A_{f}}{A_{i}}\right) \cdot 100
$$

Where $R$ is the elution, distillation or sublimation yield of the given radioisotope, $A_{f}$ and $A_{i}$ are two respective final and initial areas of the principal peaks of radioactive activities at a given acquisition time.

The result adopted for each study of the purification steps corresponds to the arithmetic averages of representative experiments among the others. 
In the complete radioisotope purification route tests, total yields were obtained by successively multiplying the yield means of the steps involved by equation 2 :

$$
R_{t}=R_{1} \cdot R_{2} \cdot R_{(n)}
$$

Where $R_{t}$ is the total recovery yield of the radioisotope and $R(1,2, \ldots, \eta)$ corresponds to the arithmetic means of the yields in the purification steps of the tested routes.

\section{RESULTS AND DISCUSSION}

As mentioned previously, on the first step of both routes were used ion-exchange columns filled with Dowex resin. At this step, ${ }^{99}$ Mo present in solution as molybdate ions $\left(\mathrm{MoO}_{4}^{2-}\right)$ was held by the resin, while aluminum ions and other contaminants produced via alkaline dissolution of ${ }^{235} \mathrm{U}$ targets in significant concentrations remained in the solution, which was called "effluent". The retained ${ }^{99}$ Mo was recovered by elution of $\mathrm{Na}_{2} \mathrm{SO}_{4}$ solution.

In the second step, the routes presented different techniques for the purification of ${ }^{99} \mathrm{Mo}$. In the MR1 route, a selective chelating column was used retaining Mo-SCN complex, achieving the best separation results for ${ }^{99} \mathrm{Mo}$ from contaminants. On the other hand, in the MR2 route, the major decontamination happened in the sublimation process. In both routes, the alumina ran as a final concentration step of the ${ }^{99}$ Mo solution.

\subsection{MR1 route}

The final yields of elution, effluent, and wash solutions obtained after the first column packed with Dowex resin and $\mathrm{Na}_{2} \mathrm{SO}_{4}$ eluting solution are shown in Table 1. 
Table 1: Elution results of ${ }^{99} \mathrm{Mo}$ and contaminants in the Dowex resin at the MR1 route.

\begin{tabular}{lccccc}
\hline \multicolumn{1}{c}{ Experiments } & ${ }^{\mathbf{9 9}} \mathbf{M o}(\boldsymbol{\%})$ & ${ }^{131} \mathbf{I}(\boldsymbol{\%})$ & ${ }^{103} \mathbf{R u}(\boldsymbol{\%})$ & ${ }^{121} \mathbf{T e}(\%)$ & ${ }^{{ }^{5} \mathbf{Z r}(\%)}$ \\
\hline Effluent 1 & 0.304 & 1.71 & 92.6 & 82.7 & 68.8 \\
Effluent 2 & 0.402 & $<\mathrm{DL}$ & 72.4 & 78.8 & 86.3 \\
Average & $0.353( \pm 0.0490)$ & - & $82.5( \pm 10.1)$ & $80.8( \pm 1.90)$ & $77.5( \pm 8.75)$ \\
Wash $1 \mathrm{OH}^{-}$ & 0.108 & 0.102 & 0.501 & 2.30 & 1.81 \\
Wash $2 \mathrm{OH}^{-}$ & $<\mathrm{DL}$ & $<\mathrm{DL}$ & 3.50 & 2.10 & 1.79 \\
Average & - & - & $2.00( \pm 1.50)$ & $2.20( \pm 0.100)$ & $1.80( \pm 0.100)$ \\
Wash $1 \mathrm{H}_{2} \mathrm{O}$ & $<\mathrm{DL}$ & $<\mathrm{DL}$ & $<\mathrm{DL}$ & $<\mathrm{DL}$ & $<\mathrm{DL}$ \\
Wash $2 \mathrm{H}_{2} \mathrm{O}$ & $<\mathrm{DL}$ & $<\mathrm{DL}$ & 0.106 & 0.504 & $<\mathrm{DL}$ \\
Average & - & - & - & - & - \\
Elution 1 & 99.0 & $<\mathrm{DL}$ & 0.408 & 0.901 & 9.09 \\
Elution 2 & 98.4 & 0.763 & 2.99 & 4.10 & 5.50 \\
Average & $98.7( \pm 0.300)$ & - & $1.70( \pm 1.29)$ & $2.50( \pm 1.60)$ & $7.30( \pm 1.80)$ \\
\hline
\end{tabular}

$<\mathrm{DL}=$ under detection limit.

The results indicated a low concentration of the ${ }^{99} \mathrm{Mo}$ in the effluent samples and high retention of it in the resin. The ${ }^{99}$ Mo recovery was greater than $90 \%$ after the final elution, confirmed by the low loss observed after the percolation of the loading solutions and the washes. For the other contaminants, the total of elimination (effluent + washes) was about $79.3 \%$ for ${ }^{95} \mathrm{Zr}, 82.9 \%$ for ${ }^{121} \mathrm{Te}$, and $84.5 \%$ for ${ }^{103} \mathrm{Ru}$. Due to the low concentrations of the contaminants in some samples, their radioactivity measurements presented the results lower than the limit of detection $(<D L)$, in the conditions applied. The Dowex resin was significant for the ${ }^{99}$ Mo separation from the other fission elements present in the initial process solution.

In addition, the adoption of $\mathrm{Na}_{2} \mathrm{SO}_{4}$ solution for the ${ }^{99}$ Mo elution was important because it does not lead to a chemical interference in the ${ }^{99}$ Mo complexation reactions, which would affect the next separation by chelation chromatography [14]. In this step, the complexation of the ${ }^{99}$ Mo with thiocyanate ions was performed using the eluted solution from the Dowex column. The obtained results in this process are presented in Table 2. 
Table 2: Elution yields of ${ }^{99}$ Mo in the Chelex resin at the MR1 route.

\begin{tabular}{lc}
\hline \multicolumn{1}{c}{ Experiments } & ${ }^{\mathbf{9 9} \mathbf{M o}(\%)}$ \\
\hline Effluent 1 & $<\mathrm{DL}$ \\
Effluent 2 & $<\mathrm{DL}$ \\
Average & - \\
Wash 1 & 2.30 \\
Wash 2 & 1.82 \\
Average & $2.06( \pm 0.240)$ \\
Elution 1 & 96.2 \\
Elution 2 & 98.4 \\
Average & $97.3( \pm 1.10)$ \\
\hline <DL = under detection limit.
\end{tabular}

The molybdenum recovery was also elevated in this step, presenting elution average higher than $97 \%$ and ${ }^{99}$ Mo loss about $2 \%$, during the washes. The measure of the contaminants' activities indicated values lower than the limit of detection (DL).

The alumina column was used to reduce the concentrations of the remaining contaminants, as well as the elimination of possible residues from the hoses, connections, and resins. Besides, the capacity to concentrate the ${ }^{99} \mathrm{Mo}$ in the final eluted solution also was observed. The recovery of the ${ }^{99}$ Mo was approximately $88 \%$, revealing the lower results than the previous columns, however, the purity of the sample improved, once the activities of the contaminants were under the limit of detection. The results of the samples obtained from alumina column are shown in Table 3. 
Table 3: Elution results of ${ }^{99} \mathrm{Mo}$ in the alumina at the MR1 route.

\begin{tabular}{|c|c|}
\hline Experiments & ${ }^{99} \mathrm{Mo} \mathrm{( \% )}$ \\
\hline Effluent 1 & 0.903 \\
\hline Effluent 2 & 0.300 \\
\hline Average & $0.602( \pm 0.302)$ \\
\hline Wash $1 \mathrm{OH}^{-}$ & 0.30 \\
\hline Wash $2 \mathrm{OH}^{-}$ & 0.40 \\
\hline Average & $0.353( \pm 0.0490)$ \\
\hline Wash $1 \mathrm{H}_{2} \mathrm{O}$ & 0.505 \\
\hline Wash $2 \mathrm{H}_{2} \mathrm{O}$ & 0.204 \\
\hline Average & $0.354( \pm 0.150)$ \\
\hline Elution 1 & 89.1 \\
\hline Elution 2 & 86.7 \\
\hline Average & $87.9( \pm 1.20)$ \\
\hline
\end{tabular}

The yields considering the duplicate results in each step and the entire MR1 route also were calculated and are shown in Table 4. The final yield of ${ }^{99}$ Mo in the MR1 route was above $80 \%$, besides the high purity demonstrated by the low radioactivity of the contaminants. The total process time, considering all purification steps and material transfers, was about 7 hours.

Table 4: Steps and total yields of the MR1 route.

\begin{tabular}{ccccc}
\hline Step & $\mathbf{1}$ & $\mathbf{2}$ & $\mathbf{3}$ & Total \\
\hline Yield $(\%)$ & $98.7( \pm 0.300)$ & $97.3( \pm 1.10)$ & $87.9( \pm 1.20)$ & $84.4( \pm 2.36)$ \\
\hline
\end{tabular}

The MR1 arrangement presented advantages in comparison with the so-called Sameh process, in which two redundant chelating columns are used [12].

\subsection{MR2 route}

For the ${ }^{99}$ Mo recovery from the Dowex column in the MR2 route, the $\mathrm{KHCO}_{3}$ solution was applied instead of $\mathrm{Na}_{2} \mathrm{SO}_{4}$. The potassium bicarbonate solution was chosen considering the next purification step, once the sulfate as eluent affects the ${ }^{99}$ Mo retention in the alumina, increasing the loss in the effluent [14]. The results for these experiments are shown in Table 5. 
Table 5: Elution results of ${ }^{99} \mathrm{Mo}$ and contaminants in the Dowex resin at the MR2 route.

\begin{tabular}{|c|c|c|c|c|c|}
\hline Experiments & ${ }^{99} \mathrm{Mo} \mathrm{( \% )}$ & ${ }^{131} \mathrm{I}(\%)$ & ${ }^{103} \mathrm{Ru}(\%)$ & ${ }^{121} \mathrm{Te}(\%)$ & ${ }^{95} \mathrm{Zr}(\%)$ \\
\hline Effluent 1 & 0.105 & 0.200 & 85.1 & 87.3 & 70.5 \\
\hline Effluent 2 & 1.80 & 0.104 & 72.4 & 65.6 & 64.5 \\
\hline Average & $0.952( \pm 0.848)$ & $0.152( \pm 0.0480)$ & $78.7( \pm 6.35)$ & $76.4( \pm 10.8)$ & $67.5( \pm 3.00)$ \\
\hline Wash $1 \mathrm{OH}^{-}$ & $<\mathrm{DL}$ & $<\mathrm{DL}$ & 1.10 & 3.20 & 0.400 \\
\hline Wash $2 \mathrm{OH}^{-}$ & 1.20 & $<\mathrm{DL}$ & 1.84 & 4.60 & 0.872 \\
\hline Average & - & - & $1.47( \pm 0.370)$ & $3.90( \pm 0.700)$ & $0.636( \pm 0.236)$ \\
\hline Wash $1 \mathrm{H}_{2} \mathrm{O}$ & $<\mathrm{DL}$ & $<\mathrm{DL}$ & 0.105 & $<\mathrm{DL}$ & 0.204 \\
\hline Wash $2 \mathrm{H}_{2} \mathrm{O}$ & $<\mathrm{DL}$ & $<\mathrm{DL}$ & 0.0230 & $<\mathrm{DL}$ & 0.0696 \\
\hline Average & - & - & $\begin{array}{c}0.0640( \pm \\
0.0410)\end{array}$ & - & $0.137( \pm 0.0672)$ \\
\hline Elution 1 & 97.4 & 0.202 & 0.302 & $<\mathrm{DL}$ & 3.50 \\
\hline Elution 2 & 96.4 & 0.301 & 2.20 & $<\mathrm{DL}$ & 7.19 \\
\hline Average & $96.9( \pm 0.500)$ & $0.252( \pm 0.0500)$ & $1.25( \pm 0.950)$ & - & $5.34( \pm 1.84)$ \\
\hline
\end{tabular}

$<\mathrm{DL}=$ under detection limit

The concentration of ${ }^{99} \mathrm{Mo}$ and contaminants in the effluent, wash and elution samples were similar to the obtained values from the same column in the route MR1.

The alumina column performed the purification of the eluted ${ }^{99} \mathrm{Mo}$ from the previous Dowex column, preparing it for the sublimation process. The acidification $(\mathrm{pH} 4)$ of the eluted samples before the percolation in the alumina bed also contributes to the volatilization of part of the residuals of ${ }^{131}$ I. The elution results are shown in the Table 6. 
Table 6: Elution results of ${ }^{99} \mathrm{Mo}$ and contaminants in the alumina at the MR2 route.

\begin{tabular}{lccc}
\hline \multicolumn{1}{c}{ Experiments } & ${ }^{\mathbf{9 9}} \mathbf{M o}(\boldsymbol{\%})$ & ${ }^{\mathbf{1 0 3}} \mathbf{R u}(\boldsymbol{\%})$ & ${ }^{\mathbf{9 5}} \mathbf{Z r}(\boldsymbol{\%})$ \\
\hline Effluent 1 & 0.902 & 2.58 & 4.60 \\
Effluent 2 & 1.30 & 4.10 & 1.60 \\
Average & $1.10( \pm 0.200)$ & $3.34( \pm 0.76)$ & $3.10( \pm 1.50)$ \\
Wash $1 \mathrm{H}_{2} \mathrm{O}$ & 0.599 & $<\mathrm{DL}$ & $<\mathrm{DL}$ \\
Wash 2 $\mathrm{H}_{2} \mathrm{O}$ & 1.20 & $<\mathrm{DL}$ & $<\mathrm{DL}$ \\
Average & $0.900( \pm 0.300)$ & - & - \\
Wash $1 \mathrm{OH}^{-}$ & 0.201 & $<\mathrm{DL}$ & $<\mathrm{DL}$ \\
Wash 2 $\mathrm{OH}^{-}$ & 0.00302 & $<\mathrm{DL}$ & $<\mathrm{DL}$ \\
Average & $0.102( \pm 0.0990)$ & - & - \\
Elution 1 & 90.2 & $<\mathrm{DL}$ & $<\mathrm{DL}$ \\
Elution 2 & 82.3 & $<\mathrm{DL}$ & $<\mathrm{DL}$ \\
Average & $86.2( \pm 3.95)$ & - & - \\
\hline$<\mathrm{DL}=$ under detection limit. & &
\end{tabular}

Approximately $1 \%$ of the ${ }^{99}$ Mo were lost in the percolation and washing of the column, as well a slight removal of ${ }^{103} \mathrm{Ru}$ and ${ }^{95} \mathrm{Zr}$ in the effluents were observed. However no contaminants were detected in the ${ }^{99}$ Mo eluted, confirming the high purification capacity of this column at this position of the route.

The ammonium hydroxide solution was adopted as the eluent for ${ }^{99} \mathrm{Mo}$ in the alumina column considering the next step. $\mathrm{NaOH}$ residues in the sample during the sublimation process produce sodium oxide along with molybdenum oxide by thermal decomposition, making difficult the ${ }^{99} \mathrm{Mo}$ recovery [13]. The sublimation yields are shown in Table 7.

Table 7: Sublimation yields of ${ }^{99}$ Mo in a tubular oven.

\begin{tabular}{lcc}
\hline \multicolumn{1}{r}{ Experiments } & Recovery $(\boldsymbol{\%})$ & Remaining (\%) \\
\hline 1 & 91.5 & 5.02 \\
2 & 88.7 & 4.30 \\
Average & $90.1( \pm 1.40)$ & $4.66( \pm 0.360)$ \\
\hline
\end{tabular}


On average, the recovery rate of ${ }^{99}$ Mo was $90 \%$. Although the experimental preparation step was carefully set up, losses during the sample evaporation were observed. The remaining residues in the crucible presented values around $4 \%$.

Results obtained in each step and the final yield of the MR2 route, considering the entire process is presented in Table 8.

Table 8: Steps and total yields of MR2 route.

\begin{tabular}{rcccc}
\hline Step & $\mathbf{1}$ & $\mathbf{2}$ & $\mathbf{3}$ & Total (\%) \\
\hline Yield $(\%)$ & $96.9( \pm 0.500)$ & $86.2( \pm 3.95)$ & $90.1( \pm 1.40)$ & $75.2( \pm 5.00)$ \\
\hline
\end{tabular}

These results could be improved by developing of specific glassware to integrate the evaporation and sublimation phases inside the oven reducing losses.

The total time demanded in the process steps, and material transfers were approximately 9 hours. This route had a final yield of $75.2 \%$ and all the contaminants presented activities below the limit of detection, thus evincing a high purification degree of ${ }^{99} \mathrm{Mo}$.

This route is similar to the ROMOL-99 process [15], but the position change of the resin (first step) and alumina (second step) columns in the process enabled to avert a labored step of the reference process [14], which involves acidifying the solution to a narrow $\mathrm{pH}$ range (0.3 to 0.5$)$ to perform on the severe working conditions due to high activities of the solutions.

In the MR2, the sublimation step took a longer time than a chelating column, so the processing time of the MR1 route was lower than the MR2. So operational improvements in the sublimation step are required, such as higher heating and cooling rates on the oven to reduce the operating time. Also, an inversion of the elution direction on the alumina column and the development of a more suitable concentrator system could contribute to the improvement of efficiency and reducing the overall process time.

Among the routes tested, the MR1 route presented the highest final purification yield of ${ }^{99} \mathrm{Mo}$ $(84.4 \%)$ and with a high decontamination degree. The results indicated that after the initial ${ }^{99} \mathrm{Mo}$ separation on anionic resin column, only two more chromatographic columns were sufficient for satisfactory purification of this radioisotope. Two comparative HPGe gamma spectra of radionuclides and their main energy peaks utilized on MR1 route are shown in fig. 3. 

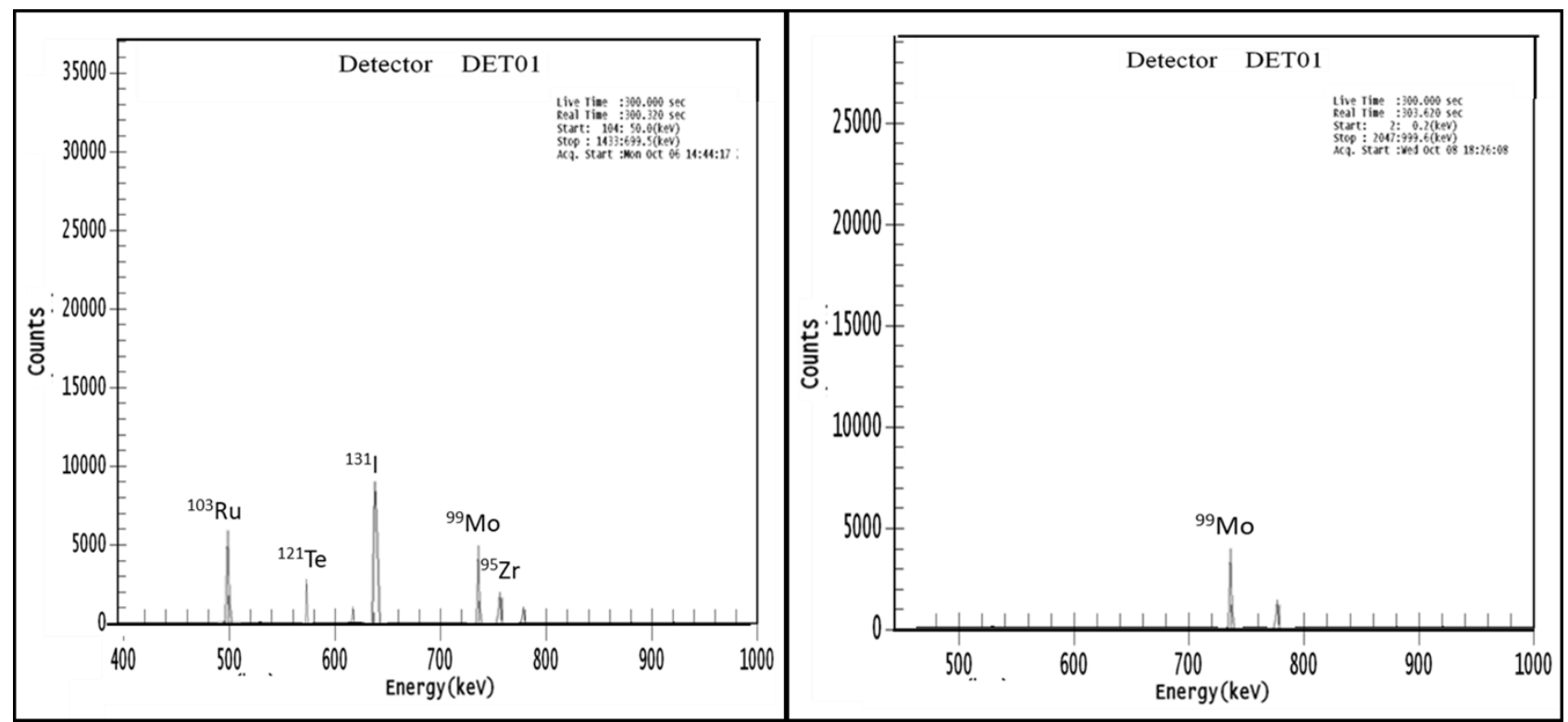

Figure 3: Gamma spectra of target and purified solutions with energy peaks of radionuclides.

On the left side the main peaks of the target solution $\left({ }^{99} \mathrm{Mo}\right.$ and contaminants) and on the right the peaks of purified solution $\left({ }^{99} \mathrm{Mo}\right)$.

This result resembles the process used in a South African producer center that also employs three chromatographic columns in its process and has a yield of approximately 85\% [16].

In the next studies, the measuring difficulties of low activities of the contaminants on the purified solution can are avoided by increasing the irradiation time of the preceding salts or making tests in the up-scale.

\section{CONCLUSIONS}

The ion exchange technique using an anionic resin column was applied in MR1and MR2 as the initial process step to purify the alkaline solution as adopted in the process adopted in Argentina and South.

The use of anionic resin in the first column of the process offered effective elimination capacity of most of the contaminants present in the loading samples as well as the possibility of a selective elution of the ${ }^{99} \mathrm{Mo}$ radioisotope in both routes. 
Besides, this process configuration avoids the pre-acidification of the loading solution, as needed in ROMOL-99 process, which represents an operation challenge due to the control of aluminum precipitation in the loading solution under critical conditions.

Between the routes tested, MR1 route presented the highest final ${ }^{99}$ Mo recovery efficiency, high decontamination degree and a shorter process time compared to the MR2 route.

The results indicate the possibility of up scaling tests of MR1 route as a short and efficient production process using only three chromatographic columns, like in South Africa's process.

The results also provide subsidies for further purification investigations on pilot cells, targeting the production at BMR facilities.

\section{ACKNOWLEDGMENT}

The authors are grateful for financial support from the Conselho Nacional de Desenvolvimento Científico e Tecnológico (CNPq, Brazil).

\section{REFERENCES}

[1] SAHA, G. B. Fundamentals of nuclear pharmacy, 5 Ed. New York, N.Y.: Springer, 2003.

[2] AHMAD, M.; VANDEGRIFT, G.; CRISTINI, P. Molybdenum-99 ( ${ }^{99}$ Mo): Past, Present and Future”. Science and Technology of Nuclear Installations, v. 2014, p. 1-3, 2014.

[3] National Academies of Science, Engineering, and Medicine (USA). Opportunities and Approaches for Supplying Molybdenum-99 and Associated Medical Isotopes to Global Markets: Proceedings of a Symposium. Washington, DC: The National Academies (2018).

[4] SHITAKA, I.; IGUCHI, A. Production of ${ }^{99}$ Mo and its applications in nuclear medicine. Journal of Radioanalytical and Nuclear Chemistry, v. 102, p. 533-550, 1986.

[5] TAUHATA, L.; SALATI, I.; DIPRIZIO, R.; DIPRIZIO, M. A. R. R. Radioproteção e Dosimetria: Fundamentos, 5 rev. Rio de Janeiro: IRD/CNEN, 2003.

[6] AQUINO, R. A.; VIEIRA, F. M. M. Molibdênio-99, Crise e Oportunidade, Scientific American, v. 98, p. 82, 2010.

[7] PERROTA, J. A.; A. J. SOARES. RMB: The New Brazilian Multipurpose Research Reactor. Atomwirtschaft, v. 60 (1), p. 30-34, 2015.

[8] SAMEH, A.; ACHE, H. J. Production techniques for fission molybdenum-99. Radiochimica Acta, v. 41, p. 65-72, 1987. 
[9] DITTRICH, S. History and actual state of non-HEU fission-based Mo-99 production with lowperformance research reactors. Science and Technology of Nuclear Installations, v. 2013, Article ID 514894, 2013.

[10]LEE, S. K.; BEYER, G.; LEE, J. S. Development of industrial-scale fission ${ }^{99}$ Mo production process using low enriched uranium target. Nuclear Engineering and Technology, v. 48, p. 613-623, 2016.

[11]CRISTINI, P. R.; COLS, H. J.; BAVARO, R.; BRONCA, M.; CENTURIÓN, R.; CESTAU, D. Production of molybdenum-99 from low enriched uranium targets. In: INTERNATIONAL MEETING ON REDUCED ENRICHMENT FOR RESEARCH AND TEST REACTORS (RERTR), San Carlos, Bariloche. November 3-8, 2002.

[12] VANDERWALT, T. N.; COETZEE, P. P. The isolation of ${ }^{99}$ Mo from fission material for use in the ${ }^{99} \mathrm{Mo} /{ }^{99 m} \mathrm{Tc}$ generator for medical use. Radiochimica Acta, v. 92, p. 251-257, 2004.

[13]MUENZE, R.; BEYER, G. J.; ROSS, R.; WAGENER, G. NOVOTNY, D.; FRANKE, E. JEHANGIR, M. PERVEZ, S.; MUSHTAQ, A. The fission-based ${ }^{99}$ Mo production process ROMOL-99 and its application to PINSTECH Islamabad. Science and Technology of Nuclear Installations, v. 2013, p. 1-9, 2013.

[14] LAVINAS, T. Purificação do molibdênio-99, obtido a partir da fissão do urânio-235, utilizando-se a resina Chelex-100. Msc Science IPEN-USP, São Paulo, 1998.

[15]BOYD, R. E. Technetium-99m generators: the available options. The International Journal of Applied Radiation and Isotopes, v. 33, p. 801-809, 1982.

[16] ANKITA, R.; ABHISHEK, K. S.; PRADEEP, K.; CHARYULU, M. M.; TOMAR, B. S.; RAMAKUMAR, K. L. Studies on separation and purification of fission ${ }^{99}$ Mo from Neutron Activated Uranium Aluminum Alloy. Applied Radiation and Isotopes, v. 89, p.186-191, 2014. 